\title{
КОМПЛЕКСНЫЙ РЕТРОСПЕКТИВНЫЙ АНАЛИЗ СТРУКТУРЫ И ДИНАМИКИ РАЗВИТИЯ ДЕРЕВООБРАБАТЫВАЮЩЕЙ ПРОМЫШЛЕННОСТИ ВЬЕТНАМА
}

\author{
(C) 2020 Чан Тхи Тхань Тхюи \\ Высшая инженерно-экономическая школа \\ Санкт-Петербургский политехнический университет Петра Великого (СПбПУ), \\ Россия, Санкт-Петербург \\ E-mail: thuytrannvcard@gmail.com \\ (c) 2020 Дегтерева Виктория Анатольевна \\ доктор экономических наук, профессор, Высшая инженерно-экономическая школа \\ Санкт-Петербургский политехнический университет Петра Великого (СПбПУ), \\ Россия, Санкт-Петербург \\ E-mail: degtereva_va@spbstu.ru
}

В статье анализируется развитие деревообрабатывающей промышленности Вьетнама в исторической ретроспективе, которое привело к настоящему времени к динамичному росту числа деревообрабатывающих предприятий. Сделан вывод об основных проблемах отрасли: низкой автоматизации, большой текучести квалифицированных кадров, отсутствии специализации среди предприятий. Разнообразный ассортимент продукции из дерева удовлетворяет внутренний и внешний спрос, что обуславливает уникальные характеристики вьетнамских деревообрабатывающих предприятий, в свою очередь вызывающих необходимость формирования многомерной и чувствительной к изменениям внешней среды системы оценки эффективности бизнес-процессов деревообрабатывающих предприятий Вьетнама.

Ключевые слова: промышленность, деревообрабатывающая промышленность, Вьетнам, эффективность бизнес-процессов

В первую очередь необходимо рассмотреть период становления и первичного развития деревообрабатывающей промышленности Вьетнама. По мнению Пола Муранда (Paul Maurand), в 1943 году площадь лесов Вьетнама составляла около 14352000 гектаров (общая площадь земли Вьетнама - 33090000 гектаров). Хотя во Вьетнаме много лесов, «лесная» политика французов в то время заключалась в основном в лесопользовании для сбора налогов и эксплуатации лесов в колониях для удовлетворения потребностей Франции, а инвестиций в обрабатывающую промышленность во время французской оккупации Вьетнама было немного. Тогда деревообрабатывающая промышленность во Вьетнаме развивалась очень медленно, количество предприятий деревообрабатывающей промышленности было невелико, предприятия были маломасштабные, использовали неэффективные рудиментарные методы деятельности.

В период антифранцузского и антиамериканского сопротивления с 1945 до 1975 гг. [6] сектор лесного хозяйства начал расширяться, были построены новые предприятия деревообраба- тывающей промышленности, производства фанеры и консервации сырой древесины. К 1975 году на севере Вьетнама было создано 135 деревообрабатывающих предприятий для обслуживания населения. Многие деревообрабатывающие предприятия имели собственные цеха по производству мебели. Деревообрабатывающие предприятия Вьетнама в основном малые или средние. Из 135 предприятий деревообрабатывающих промышленных только 8 предприятий имеют масштаб производства 20000-50000 м³ круглого леса в год, 35 предприятий - 5000$10000 \mathrm{~m}^{3}$ круглого леса в год, 66 предприятий производства - 1500-3000 м³ круглого леса в год и 23 предприятия с масштабом производства менее $1000 \mathrm{~m}^{3}$ круглого леса в год. В южном регионе Вьетнама деревообрабатывающая промышленность развита слабо. Появляется немного промышленных деревообрабатывающих предприятий с производственной мощностью около $600000 \mathrm{~m}^{3}$ круглого леса в год. В этот период деревообрабатывающие предприятия начали отправлять древесную продукцию на экспорт.

В период осуществления плана экономи- 
ческого развития 1976-1980 гг. и 1980-1985 гг. предприятия деревообрабатывающей промышленности были реорганизованы для обеспечения продукцией из древесины в соответствии с целями государственного планирования, первоначально как предприятия по переработке и поставке лесной продукции. Поставки древесной продукции расширились по регионам. В результате количество промышленных деревообрабатывающих предприятий быстро росло и развивалось вместе с объемом заготовленной, переработанной и экспортированной продукции из древесины.

В период 1986-1995 гг. Вьетнам осуществляет многосекторальную стратегию экономического развития в секторе лесного хозяйства и деревообрабатывающей промышленности. Поэтому в населенных пунктах появился ряд деревообрабатывающих предприятий для экспорта продукции из древесины. Однако промышленные деревообрабатывающие предприятия не следуют генеральному плану лесного сектора Вьетнама, что приводит к значительному уничтожению лесов. Ради сохранения лесов во Вьетнаме были приняты меры по охране лесов, развитию деревообрабатывающей промышленности, изучению и обзору экспорта продукции из древесины.

В период с 1995 года по настоящее время с учетом тенденций развития страны благодаря механизмам и политике поощрения переработки и экспорта древесной продукции, деревообрабатывающая промышленность активно развивалась в направлении увеличения экспорта. На данный момент деревообрабатывающие предприятия Вьетнама в основном занимаются производством мебели и производством деревянных досок (фанеры, плиты), пиломатериалов и паллет для внутреннего рынка и экспорта. Продукты из древесины Вьетнама доступны на многих крупных рынках по всему миру. Основными рынками Вьетнама являются США (на их долю приходится 43\% или 3,27 млрд. долларов США), ЕС (на долю которого приходится 28-44\%) от доли экспорта продукции из древесины Вьетнама на рынке в 2017 году. За период с 2005 по 2016 год количество деревообрабатывающих предприятий увеличилось почти в 3 раза. На рисунке 1 представлена динамика развития деревообрабатывающей промышленности Вьетнама в рамках описываемого периода [3].

Основными причинами данного динамичного роста изменения числа деревообрабатывающих предприятий Вьетнама можно считать общее улучшение бизнес-среды Вьетнама, рост интегрированности экономики Вьетнама в мировую экономику, рост объема иностранных инвестиций в исследуемую отрасль, а также общий рост спроса на отдельные группы изделий. Одна-

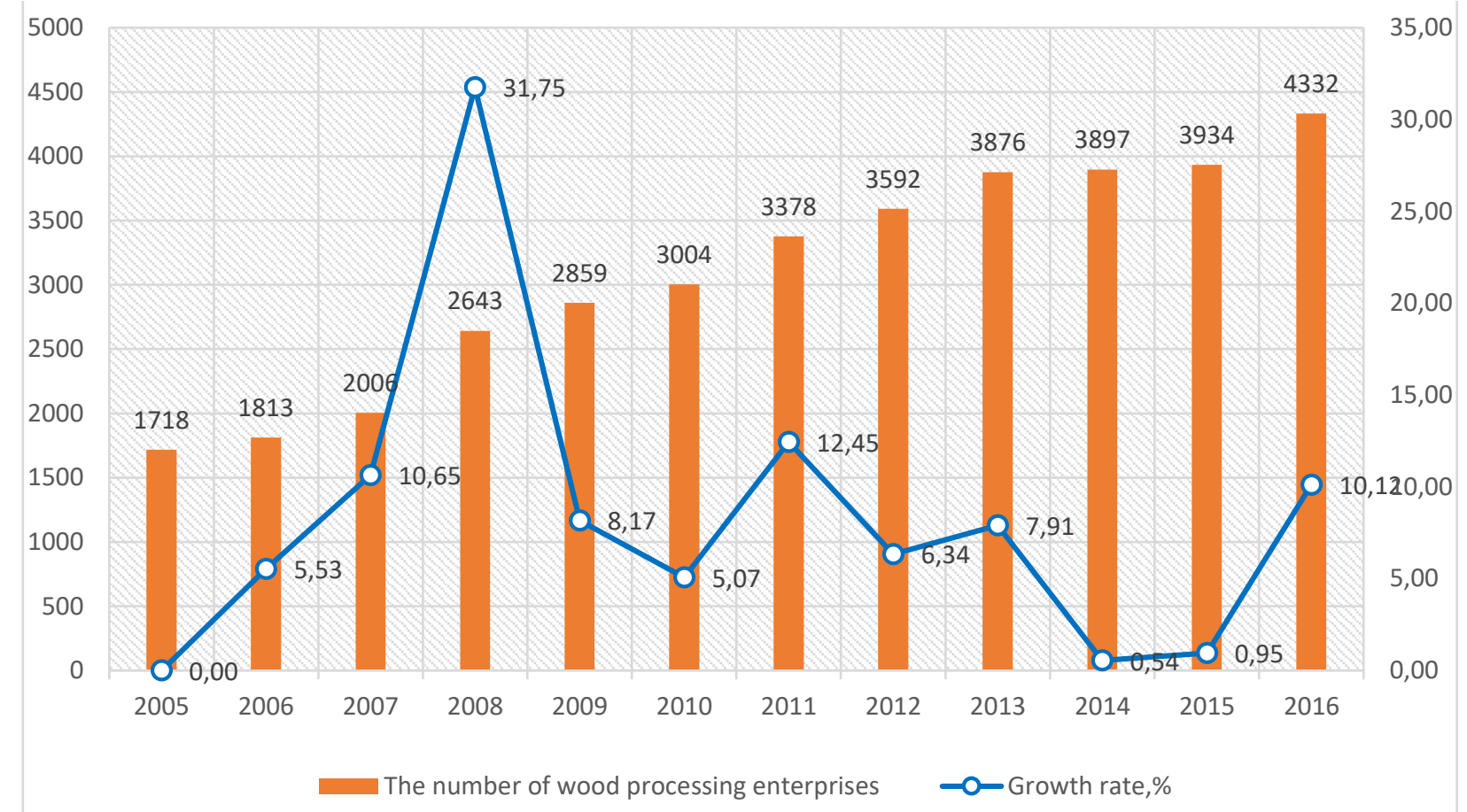

Рисунок 1. Динамика изменения числа деревообрабатывающих предприятий Вьетнама в период с 2005 по 2016 гг. 
ко несмотря на то, что деревообрабатывающие предприятия во Вьетнаме усиленно развиваются, они существуют в основном в форме малых и средних предприятий. Кроме того, большинству деревообрабатывающих предприятий приходится выполнять все процессы от распиловки до отделки изделий из древесины без специализации среди предприятий.

С точки зрения мощности оборудования и технологии обработки древесины около 80\% оборудования пиления, сушки древесины, вспомогательного оборудования изготовлено во Вьетнаме, остальное оборудование главным образом импортировано из Тайваня, Италии, Китая, Германии и других стран. Что касается автоматизации, то 100\% производственных линий предприятий деревообрабатывающей промышленности Вьетнама полуавтоматические, 30\% из них имеют уровень передовой технологии, а $70 \%$ - средний уровень технологии [4]. Большая часть оборудования находится в эксплуатации от 6 до 15 лет (около 63-75\%) [2, 7].

Численность работников деревообрабатывающей промышленности Вьетнама нестабильна. Деревообрабатывающие предприятия не имеют политики привлечения рабочей силы для стабилизации производства, эксперты и технические работники не отвечают растущим требованиям отрасли, что представлено на рисунке 2. Согласно данным, приведенным на рисунке 2, деревообрабатывающая промышленность Вьетнама по-прежнему представлена в основном простым трудом, хотя это важный производственный сектор, который вносит значительный вклад в экспортный оборот Вьетнама. Причина в том, что экспортируемая из Вьетнама продукция из древесины - это в основном мебель. Кроме того, рабочие с высшим образованием в основном сосредоточены на государственных предприятиях и в крупных компаниях. Очевидно, что, если большинство работников не имеют образования, это отрицательно влияет на производительность труда, а эффективность производства будет низкой.

В целом, деревообрабатывающие предприятия Вьетнама значительно изменились с 2010 по 2016 гг. В 2015 году группа деревообрабатывающих предприятий с капиталом от 1 млрд. донгов до 20 млрд. донгов (малые предприятия) составила $26,28 \%$ (26,92\% в 2016 году). На деревообрабатывающие предприятия с капиталом менее 1 млрд. донгов (микропредприятия) приходилась наибольшая доля, которая составила 29,03\% в 2015 году и 29,57\% в 2016 году. Деревообрабатывающие предприятия с капиталом от 20 млрд. до 100 млрд. донгов (средние предприятия) составляли $27,3 \%$ в 2015 году и $26,48 \%$ в 2016 году. Группа предприятий с капиталом свыше 100 млрд. донгов (крупные предприятия) составляла 17,39\% в 2015 году и снизилась до 17,04\% в 2016 году.

Процесс интеграции и международного экономического сотрудничества, в котором больше всего выделяется вступление Вьетнама в ВТО, открыло много возможностей для развития деревообрабатывающей промышленности Вьетнама, но в то же время сопряжено с множеством трудностей. Поэтому для достижения ожидаемых результатов предприятиям необходимо иметь правильные и разумные стратегии для усиления эффективности бизнес-процесса, повышения конкурентоспособности предприятий.

Лесной комплекс во Вьетнаме, включающий лесное хозяйство и лесопромышленные отрасли по заготовке и переработке древесины, занимает важное место в экономике страны. Каждая отрасль имеет свои особенности развития. Так, во Вьетнаме давно развивалась деревообработка и появились традиционные деревообрабатывающие села. Деревообрабатывающая промышленность во Вьетнаме - отрасль лесной промышленности, которая включает лесозаготовку, первичную обработку леса, производство мебели, производство садовой мебели, производство художественных изделий из дерева и т.д. Разнообразный ассортимент продукции из дерева удовлетворяет внутренний и внешний спрос.

Вьетнамские деревообрабатывающие предприятия имеют следующие ключевые характеристики:

1. Продукция из дерева, на которую большое предложение на рынке, должна удовлетворять основные потребности клиентов. Человек давно научился использовать дерево для удовлетворения ежедневных потребностей, например, для строительства дома, украшения, изготовления бытовых повседневных предметов (столы, стулья, шкафы и др.), и пользоваться оставшимися частями дерева и деревом низкого качества как топливом. Некоторые виды древесины с определенной текстурой и ароматом активно используются для изготовления кустарных изделий и украшения домов. Таким образом, нельзя отрицать важность продукции из дерева для повсед- 
Классификация по времени заключения договора

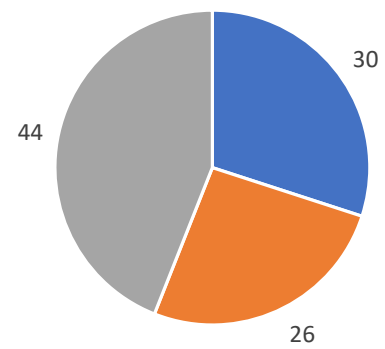

- Контрактные работники не указывают срок - Трудовой договор на 1-3 лет Сезонный труд

Классификация по видам труда

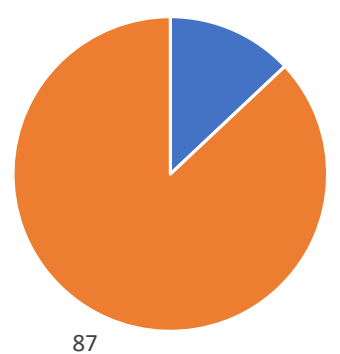

- Косвенный труд: административный, офисный च Прямой труд: производство

Классификация по уровню образования

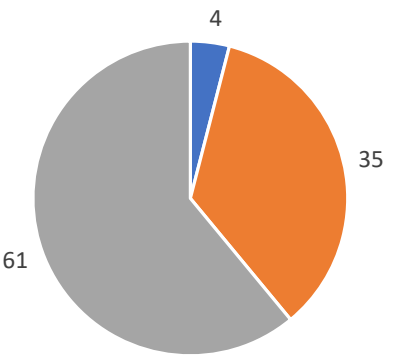

- Высшее образование

- Среднее профессиональное образование

- Не имеют образования

Классификация по полу

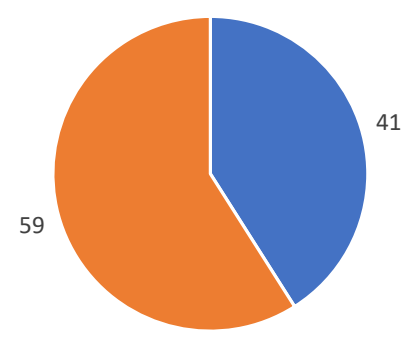

- Работники-женщины = Работники-мужчины

Рисунок 2. Специфика ресурсного обеспечения труда в рамках деревообрабатывающей промышленности Вьетнама [1] 
невных потребностей человеческой жизни.

Сейчас по мере роста общества спрос на деревянные продукции тоже растет, но предложение на древесину не может ответить на спрос деревообрабатывающих предприятий и населения. Поэтому с целью удовлетворения высоких требований производятся новые материалы, такие как искусственные доски, фанера, древесные гранулы и т.д. Много современных фабрик и деревообрабатывающих предприятий производят все это в большом количестве. Они используют дешевое местное сырье и дешевую рабочую силу;

Создание малых предприятий или домашних хозяйств было неизбежно благодаря передаче профессии из поколения в поколение и работе крестьян в свободное время. Открытие цехов или предприятий малого и среднего бизнеса зависит от спроса на рынке, капитала домашних хозяйств и сел, инвестиций в некоторые пильные машины, строгальные станки, полировальные машины, сверлильные станки, краскораспылители и т.д. Это показывает гибкость деятельности производства и бизнеса, высокую квалификацию рабочей силы, рациональное управление, соответствующее рынку. Однако минус такого масштаба производства - трудность в реализации крупных иностранных контрактов, поэтому главное производство этих предприятий находится на аутсорсинге. Они не могут создавать собственный бренд, их товары продаются через посредника, и они еще не в состоянии обращать внимание на обучение персонала деревообработке;

2. Производство разнообразных видов продукции в соответствии с потребностями населения. Продукция из дерева во Вьетнаме очень разнообразна по видам и формам, которые удовлетворяют потребности разных классов населения. Например: брус, древесина для строительства, изделия из дерева, изделия кустарного промысла, другие древесные материалы, искусственные доски и изделия из искусственных досок, изделия из других лесных материалов, кресла, разнообразные стулья, офисная мебель, кухонная мебель, мебель для спальни и другие.

Сегодня, когда общество развивается, потребности человека в древесине повышаются и по количеству, и по качеству, но сырье из естественных и посаженных лесов имеет тенденцию к истощению и не отвечает современным стандартам деревообработки. Деревообра- батывающая промышленность должна найти альтернативные материалы или использовать оставшиеся части древесины для переработки. Поэтому для производства древесностружечных плит, искусственных досок, таблеток, фанеры и др. была создана технология сжатия такого сырья: рисовой шелухи, кокосового волокна, древесной щепы, дров, веток, листьев, корней деревьев - всего, что до сих пор не использовалось. Так появилось новое направление для производства и переработки древесины, где раньше использовалось только сырье, взятое из естественных или посаженных лесов.

Кроме того, чтобы создать разнообразные модели долговечных изделий из дерева, разрабатываются варианты сочетания с металлами и сплавами, прикрепленными навесными приспособлениями, такими как гиацинт, ротанг, бамбук или другие альтернативные материалы, с целью повышения удобства использования продукта, а также разнообразия продукции для удовлетворения растущего спроса на внутреннем и внешнем рынках;

3. Доля затрат на сырье в общей сумме затрат на производство преобладает. В структуре затрат на производство деревообрабатывающей промышленности затраты на сырье составляют 70\% из-за ограниченного предложения сырья в стране. Это существенно влияет на эффективность бизнес-процессов деревообрабатывающих предприятий. Предприятия вынуждены тратить большие деньги на импорт сырья по высоким ценам, что значительно снижает эффективность производства;

4. Процессы производства на деревообрабатывающих предприятиях могут быть поделены на распиловку, сушку, обработку и отделку (зависит от подотраслей). Эта характеристика отличает экспортирующие деревообрабатывающие предприятия от внутренних деревообрабатывающих предприятий, так как для экспортирующих деревообрабатывающих предприятий эти этапы являются обязательными в соответствии со стандартами требований по обеспечению качества продукции страны-импортера. Между тем внутренние деревообрабатывающие предприятия не проводят распиловку, кипение, сушку отдельно, чтобы сэкономить время и затраты. Чтобы обеспечить и точно оценить эффективность бизнес-процесса, промышленные деревообрабатывающие предприятия должны специализироваться на каждом этапе производ- 
ственного процесса, а также проанализировать влияние внутренних и внешних факторов на бизнес-процессы, оценить эффективность бизнеса на каждом этапе производства;

5. Технологии, используемые в деревообработке, устарели и недостаточно эффективны. При развитии семейного бизнеса в традиционных ремесленных деревнях большая часть технологий - это ручной труд; работа требует большого мастерства от рабочих. Группа предприятий, изготавливающих художественную мебель, домашнюю мебель, в основном использует технологию ручной работы традиционными инструментами, такими как ручная пила, долото, ручная резка, требующими ловкости мастера и тонкости работы. Из-за требований производства, а также ограниченного объема инвестиционного капитала, деревообрабатывающая промышленность в деревнях и домохозяйствах ремесла невелика и подходит для развития инвестиций в семейный, малый и средний бизнес;

6. Используется рабочая сила разной квалификации. Деревообработка создала много рабочих мест и улучшила доходы трудящихся. В масштабах малых и средних предприятий частный капитал является основным. В структуре рабочей силы выпускники вузов составляют менее $10 \%$, обученные рабочие составляют 45-50\%, сезонные работники - 35-40\%.

При нынешнем положении рабочей силы, особенно для группы производителей мебели на экспорт, вопрос обучения и пополнения рабочих высокого класса, которые могут использовать современные технологии в производстве, явля- ется важным в области деревообработки. Этот вопрос также влияет на возможность повышения количества экспортной продукции и изготовления качественной древесной продукции, на создание бренда и на возможность повышения стоимости продукции.

Также, необходимо проанализировать структуру порового и внутреннего спроса на исследуемую продукцию. Мировое исследование рынка мебели 2016 (World Furniture outlook 2016), осуществлённое центром промышленных исследований (Center for Industrial Studies - CSIL) показало, что общий мировой объем продаж мебели в 2015 году составил 467,7 млрд. долларов США [10]. Средний спрос на мебель в Европе в 2015 году составила около 180 долларов США на человека, в Северной Америке - около 185 долларов США на человека, в мире - около 75 долларов США на человека. В настоящее время экспорт продукции из древесины занимает пятое место в ключевых экспортных секторах Вьетнама. Вьетнам является вторым по величине экспортером деревянной мебели в Азии и первым в Юго-Восточной Азии. Экспортный оборот мебели 70 стран в 2015 году оценивается CSIL около 137,7 млрд. долларов США, доля рынка Вьетнама составляет 5\%, занимая пятое место. Поскольку мировой экономический кризис напрямую повлиял на спрос на продукцию из древесины и объем экспорта продукции из древесины с 2009 спрос на продукцию из древесины в масштабах мировой экономики снизился на 20\%, во Вьетнаме, с 2009 года темпы роста объема экспорта продукции из древесины снизились на 6,13\% (рисунок 3).

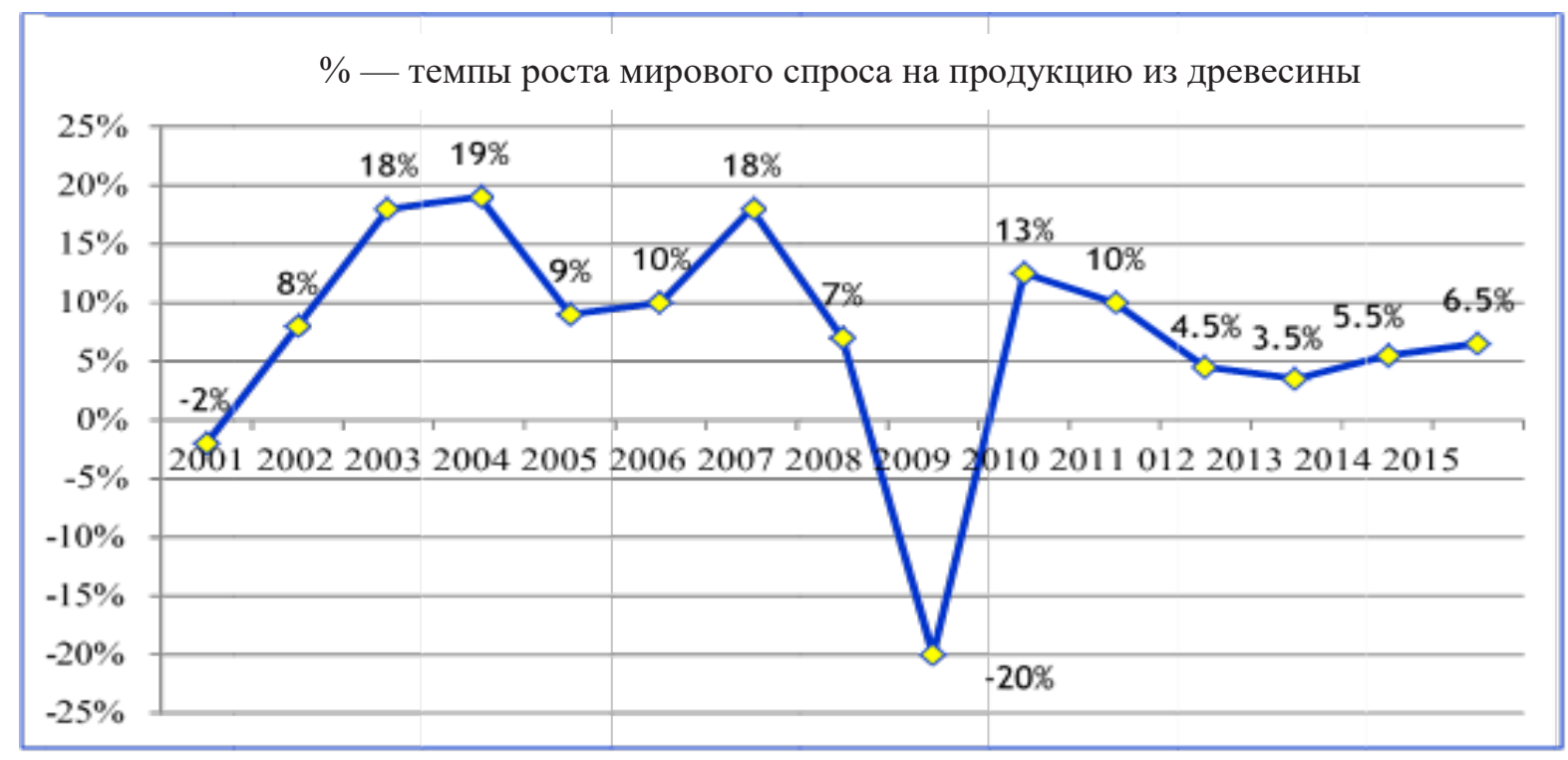

Рисунок 3. Темпы роста мирового спроса на продукцию из древесины [9] 


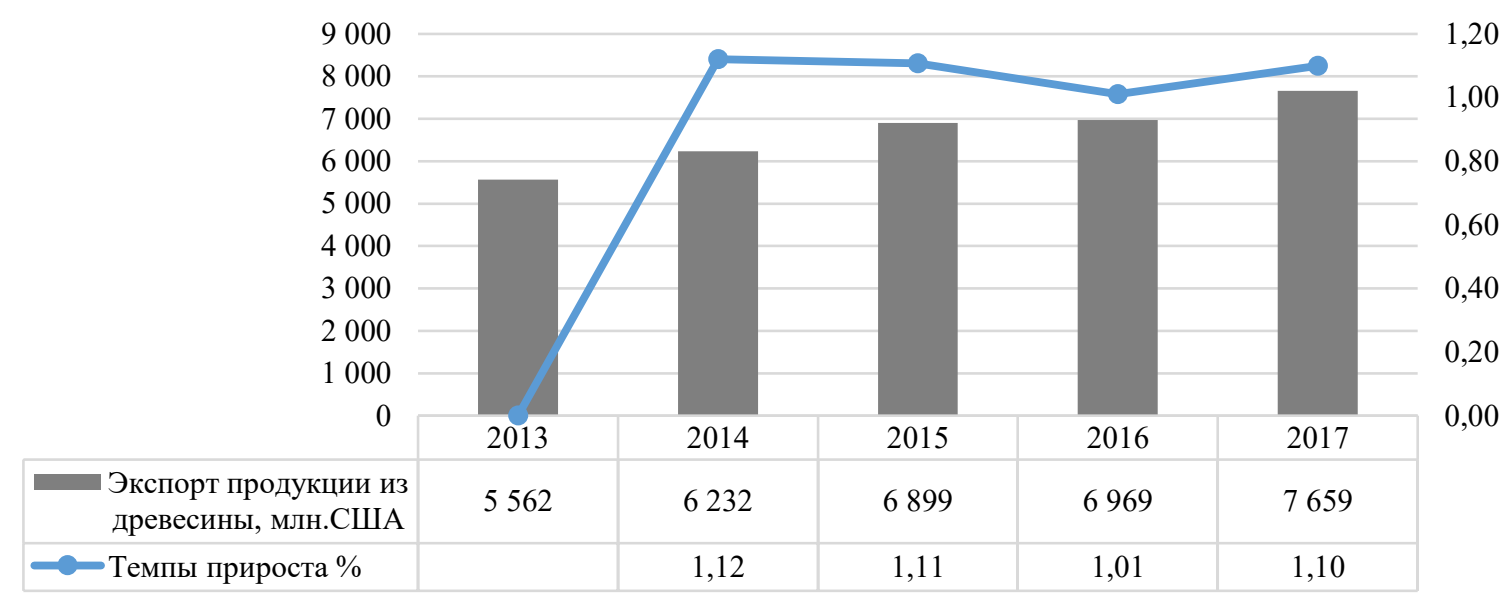

Рисунок 4. Объем экспорта продукции из древесины Вьетнама в период 2013-2017 гг. [5, 8]

До настоящего времени спрос на продукцию из древесины в мире растет, изделия из древесины считаются перспективнейшей областью развития экономики Вьетнама. Согласно таможенной статистике, продукция из древесины Вьетнама экспортируется более чем в 120 стран. В период с 2013 по 2017 год среднегодовые темпы роста составили $1,08 \%$ (рисунок 4).

В 2017 году объем экспорта продукции из древесины Вьетнама достиг почти 7,7 млрд. долларов США, что на $10 \%$ больше по сравнению с оборотом в 2016 году. Увеличение произошло в основном за счет расширения Вьетнамом экспорта мебели, щепа и фанеры.

В последние годы внутренний рынок продукции из древесины резко изменился. Продукция деревообрабатывающих предприятий была представлена на специально учрежденных отечественных ярмарках для более быстрого привлечения потребителей. Прямым следствием этого стало увеличение спроса на продукцию из древесины на внутреннем рынке. В настоящее время во Вьетнаме с населением около 96 млн. человек средний объем рынка продукции из древесины в период 2011-2016 гг. составил около 1,232 млрд. долларов США. Распределение потребления продукции из древесины на внутреннем рынке:

- Сельская местность: 70\% населения используют около 30\% продукции из древесины;

- Города: 30\% населения используют около 70\% продукции из древесины, при этом 30\% для домашних хозяйств и $40 \%$ - для строительных работ.

Вьетнам является крупным экспортером продукции из древесины, но ежегодно импортирует некоторые виды продукции для разнообразия внутреннего рынка, а также производит материалы для производства продукции из древесины на экспорт.

Таким образом, мы можем заключить, что несмотря на динамичное развитие данной отрасли как на внутреннем рынке Вьетнама, так и в рамках экспортной деятельности, существует уникальная низкотехнологическая специфика, которая подразумевает необходимость формирования более многомерной и чувствительной к изменениям внешней среды системы оценки эффективности бизнес-процессов деревообрабатывающего предприятия Вьетнама.

\section{Библиографический список}

1. Вьетнамская деревообрабатывающая промышленность приближается к крупным заказам [Электронный ресурс].- Режим доступа: http://vietnambiz.vn/nganh-go-viet-nam-chi-7-doanh-nghiep-lon-tiep-can-donhang-lon-cua-my-nhat-ban-13119.html (дата обращения 10.06.2018 г.)

2. Конников Е.А., Конникова О. А., Лукашевич Н. С. Векторная модель оценки потенциальной результативности решений, направленных на повышение устойчивости развития промышленного предприятия. Экономические науки. 2019. № 170. С. 47-50.

3. Нгуен Ван Лок Лесопромышленный комплекс Вьетнама в системе мирохозяйственных связей: современное состояние и тенденции развития: Автореф. канд. экон. наук.-СПб.: СПбГЛТА, 2016-22 с. 
4. Нгуен Т.Н. Лесной сектор экономики Вьетнама: пути модернизации и совершенствование государственной политики // Проблемы современной экономики. - 2018. - № 1.- С. 15.

5. Нгуен Тьи Дык Участие России и Вьетнама в АТЭС и АСЕАН: итоги, проблемы и трудности.- М.: ИЭ РАН, 2013 г.- С 28.

6. Обзор Вьетнамской деревообрабатывающей промышленности / [Электронный ресурс].- Режим доступа: https://cuagocongnghiephdf.com/tong-quan-nghanh-go (дата обращения: 16.08.2016)

7. Rodionov D., Konnikova O., Konnikov E. Approaches to ensuring the sustainability of industrial enterprises of different technological levels. The Journal of Social Sciences Research. 2018. T. 3. C. 277.

8. Чан Ван Хунг Развитие деревообрабатывающей промышленности на Юго-Востоке: Диссер. доктора экон. наук.-Хошимин, 2016,- 189 с.

9. Чан Тхи Хай Иен Возможности и перспективы устойчивого развития деревообрабатывающей промышленности Вьетнама / Тхи Хай Иен Чан, С. В.Терещенко // Известия Санкт-Петербургского государственного экономического университета. - 2018. - № 5 (113). - С. 36-43.

10. Ялымов С.В., Родионов Д.Г. Структура внешней среды сектора малого и среднего предпринимательства. Бизнес. Образование. Право. 2020. № 3 (52). С. 31-36. 